\title{
Artigo/Article
}

\section{Alterações ultraestruturais em larvas de Aedes aegypti submetidas ao diterpeno labdano, isolado de Copaifera reticulata (Leguminosae), e à uma fração rica em taninos de Magonia pubescens (Sapindaceae)}

\author{
Ultrastructural alterations in larvae of Aedes aegyptisubject to labdane diterpene isolated from Copaifera \\ reticulata (Leguminosae) and a fraction enriched with tannins of Magonia pubescens (Sapindaceae)
}

\section{Cleyde Ferreira Barreto Valotto ${ }^{1}$, Heloisa Helena Garcia da Silva ${ }^{1}$, Gláucia Cavasin ${ }^{2}$, Regina Geris ${ }^{3}$, Edson Rodrigues Filho ${ }^{4}$ Ionizete Garcia da Silva ${ }^{1}$}

\section{RESUMO}

Introdução: Dengue é um importante problema de saúde pública, em vários países, e tem como principal vetor o Aedes aegypti, mosquito mais adaptado às áreas urbanizadas. Apresentase, pela primeira vez, as alterações ultraestruturais em larvas de $3^{\circ}$ estádio, desse mosquito, causadas pelos larvicidas naturais, um diterpeno labdano, extraído de Copaifera reticulata, e uma fração rica em taninos catéquicos, extraída de Magonia pubescens, evidenciando o mecanismo de ação dessas substâncias. Métodos: Os experimentos foram realizados com larvas de $3^{\circ}$ estádio em solução de $0,9 \mathrm{ppm}$, do diterpeno (3- $\beta$-acetoxylabdan-8(17)-13-dien-15-óico) e de $3,7 \mathrm{ppm}$, da fração majoritária de tanino catéquico de massa molecular 864Da. Obtiveramse as substâncias através de fracionamentos cromatográficos sucessivos, identificadas por ressonância magnética nuclear de hidrogênio e espectrometria de massas. As larvas que atingiram estado letárgico foram coletadas e dissecadas e seus tubos digestórios fixados, desidratados, emblocados e polimerizados. Cortes ultrafinos foram feitos e contrastados com acetato de uranila $3 \%$ e citrato de chumbo, posteriormente, levados ao microscópio eletrônico. Resultados: As principais alterações ultraestruturais provocadas pelos diterpeno e tanino sobre larvas de Aedes aegypti foram vacuolização citoplasmática, desorganização e degeneração celular, mudança estrutural dos microvilos e deslocamento das células da lâmina basal. Conclusões: $\mathrm{O}$ diterpeno e a fração rica em taninos catéquicos provocaram a morte das larvas de Aedes aegypti através da destruição celular no intestino médio.

Palavras-chaves: Aedes aegypti. Copaifera reticulata. Magonia pubescens. Controle. Ultraestrutura.

\begin{abstract}
Introduction: Dengue is an important public health problem in many countries and its main vector Aedes aegypti, is the mosquito most adapted to urban areas. For the first time, the mechanism of action of labdane diterpenoid extracted from Copaifera reticulata and the fraction enriched of catechin tannins extracted from Magonia pubescens is demonstrated through ultrastructural alterations of Aedes aegypti larvae. Methods: Experiments were performed using a 0.9ppm solution of diterpenoid and $3.7 \mathrm{ppm}$ of the fraction as the main catechin tannin of molecular mass $846 \mathrm{Da}$. The compounds were obtained by thin layer chromatography and identified by nuclear magnetic resonance of hydrogen and mass spectrometry. Larvae that achieved lethargic state were collected and dissected. Next, they were contrasted with $1 \%$ uranyl acetate, dehydrated, embedded and polymerized. Ultrathin sections were made, mixed with $3 \%$ uranyl acetate and lead citrate and placed in an electron microscope. Results: The main ultrastructural alterations caused by the diterpenoid and by tanins in larvae of Aedes aegypti were: cytoplasmic vacuolation, alteration of microvilli, cellular aging, cell disruption and degeneration, formation of secretion vesicles and structural changes in microvilli, irregular nuclei and displacement of cells in the basal lamina. Conclusions: The fraction containing tannins and the diterpenoid caused the death of Aedes aegypti larvae by cell destruction in the midgut.
\end{abstract}

Keywords: Aedes aegypti. Copaifera reticulata. Magonia pubescens. Control. Ultrastructure.

1. Departamento Microbiologia, Imunologia, Parasitologia e Patologia, Instituto de Patologia Tropical e Saúde Pública, Universidade Federal de Goiás, Goiânia, GO. 2. Instituto de Ciências Biológicas, Universidade Federal de Goiás, Goiânia, GO. 3. Instituto de Química, Universidade Federal da Bahia, Salvador, BA. 4. Departamento de Química, Universidade Federal de São Carlos, São Carlos, SP.

Endereço para correspondência: Dr. Ionizete Garcia da Silva. Depto Microbiologia, Imunol, Parasitol e Patologia/PTSP/UFG. Caixa Postal 131, Setor Universitário, 74605-050 Goiânia, GO.

Tel: 5562 3209-6128; Fax: 5562 3261-2077

e-mail: ionizete@iptsp.ufg.br

Recebido para publicação em 02/06/2010

Aceito em 04/11/2010

\section{INTRODUÇÃO}

A dengue está entre as mais importantes arboviroses do mundo e o Aedes aegypti é o vetor reconhecido dos quatro sorotipos do vírus (Den1, $2,3,4)$. Suas manifestações clínicas variam de uma síndrome viral inespecífica até um quadro grave $\mathrm{e}$ fatal por hemorragia ou choque ${ }^{1-3}$.

A transmissão e a prevalência de dengue estão associadas às condições ecológicas e sócioambientais que propiciam a criação do vetor e o contato com o homem. Como não há vacina disponível até o momento, a principal estratégia de controle tem sido o combate ao Aedes aegypti-6. Dentre as ferramentas utilizadas, a mais prática e rápida tem sido a aplicação de inseticidas sintéticos. A pressão constante desses produtos tem levado ao aparecimento de resistência do mosquito a esses compostos ${ }^{7-10}$.

Em busca de novas alternativas para o controle do Aedes aegypti, várias pesquisas vêm sendo desenvolvidas no intuito de encontrar um inseticida eficaz com menor impacto ambiental ${ }^{11-19}$.

Neste contexto, substâncias larvicidas de Copaifera reticulata e Magonia pubescens foram isoladas, purificadas, testadas e as alterações ultraestruturais do intestino de larvas de Aedes aegypti são apresentadas em eletromicrografia de transmissão, com a finalidade de esclarecer o mecanismo de ação.

\section{MÉTODOS}

\section{Bioensaios}

Larvas de Aedes aegypti foram obtidas de uma colônia permanente, alimentadas com ração para gatos, finamente triturada, e mantida a $28 \pm 1^{\circ} \mathrm{C}$, umidade relativa de $80 \pm 5 \%$ e fotoperíodo de $12 \mathrm{~h}^{20}$. Os experimentos foram separados em três grupos: o primeiro grupo contendo o diterpenóide (ácido 3- $\beta$ acetoxi-labdan-8(17)-13-dien-15-óico) isolado do óleo-resina de Copaifera reticulata ${ }^{18}$ na concentração 
de 0,9ppm, o segundo contendo uma fração enriquecida em taninos condensados, cuja unidade monomérica principal é uma catequina (flavan-3-ol) encontrada no córtex do caule de Magonia pubescens ${ }^{16}$, a 3,7ppm e, por último, o controle, contendo somente água destilada. Todos os experimentos foram realizados em duplicata.

Foram colocadas 20 larvas em cada frasco, imediatamente após a ecdise para o $3^{\circ}$ estádio, contendo $30 \mathrm{~mL}$ das soluções dos compostos a serem testados. Estes experimentos foram deixados por $22 \mathrm{~h}$, período determinado em experiência piloto para evidenciar as alterações, e somente as larvas em estágio de letargia foram coletadas para os estudos morfológicos.

\section{Secções}

As larvas coletadas foram dissecadas sob estereomicroscópio (MZS-250), em uma gota do fixador apropriado e seus tubos digestórios foram retirados e fixados para microscopia eletrônica de transmissão, em $2 \%$ glutaraldeído, $2 \%$ paraformaldeído, $3 \%$ sacarose em tampão cacodilato de sódio 0,1M pH 7,2.

Após esta fixação, o material foi lavado no tampão cacodilato de sódio (2 lavagens de 30min) e pós-fixado em tetróxido de ósmio $1 \%$ em cacodilato de sódio $0,1 \mathrm{M}$, por $2 \mathrm{~h}$, a $4^{\circ} \mathrm{C}$. Depois submetido a duas lavagens por $30 \mathrm{~min}$ com o tampão cacodilato de sódio $0,1 \mathrm{M}$. Em seguida, foi colocado em álcool $10 \%$ como preparativo para a contrastação em bloco. Esta foi feita com acetato de uranila a 1\%, em álcool $10 \%$, à temperatura ambiente overnight. O material foi lavado com água destilada e submetido ao processo de desidratação em concentrações crescentes de álcool a 70, 80, 90, 95, 100\% (3x), álcool + óxido de propileno (volume/volume) e óxido de propileno por $15 \mathrm{~min}$ cada. Após a desidratação os tubos digestórios foram deixados em óxido de propileno+spurr (volume/volume), e spurr puro, por 1h. Este último procedimento foi repetido por três vezes, e em seguida deixado em spurr por mais $24 \mathrm{~h}$, emblocado e polimerizado por $24 \mathrm{~h}$ a $70^{\circ} \mathrm{C}^{21-23}$.

Os blocos foram seccionados em ultramicrótomo Leica Ultracult UCT, transferidos para lâminas e corados com azul de toluidina para rastreamento das alterações em microscopia de luz. Em seguida cortes ultrafinos foram colocados em telinhas de cobre recobertas com colódio/carbono, contrastadas com acetato de uranila a $3 \%$, por $30 \mathrm{~min}$ e solução de citrato de chumbo, por $10 \mathrm{~min}$ à temperatura ambiente. Após a secagem, os cortes foram levados ao microscópio eletrônico de transmissão para serem examinados e eletromicrografados.

\section{RESULTADOS}

No grupo controle, o intestino médio ou mesêntero de larvas de $3^{\circ}$ estádio de Aedes aegypti apresentou três partes distintas: anterior, mediana e posterior. As células da região anterior (Figura 1A) apresentaram-se cúbicas com núcleo esférico evidenciando áreas de eurocromatina e heterocromatina e nucléolo distinto. No citoplasma destas células, foi possível observar uma grande quantidade de mitocôndrias de formatos irregulares (Figura 1A e B). A região apical destas células demonstrou a presença de curtas microvilosidades (Figura 1C).

A região mediana também se apresentou formada por um epitélio cilíndrico (Figura 1D) com a presença de inúmeras pregas na lâmina basal destas células, indicando a realização de trocas iônicas nesta região (Figura 1E). A região apical destas células mostrou microvilosidades mais altas que as da região anterior (Figura 1F). O núcleo apresentou-se grande e com cromatina descondensada, mostrando características de intensa atividade celular (Figura 1E).

A região posterior apresentou-se formada por células colunares (Figura 1G), com inúmeros vacúolos digestivos e figuras mielínicas no seu interior na porção basal (Figura 1H). As microvilosidades apicais nesta região mostraram-se longas e finas (Figura 1I).

Mudanças morfológicas nas células do mesêntero das larvas foram notadas com $22 \mathrm{~h}$ de exposição ao diterpeno. Na região anterior, as células apresentaram-se mais baixas que as do grupo controle (Figura 2A), com região basal e apical demostrando certo grau de conservação (Figuras 2B e 2C). A Figura 2B mostra em detalhe $\mathrm{o}$ aspecto de integridade das mitocôndrias desta região.

As células da região mediana (Figura 2D) apresentaram alto grau de destruição, com evidente desorganização celular e notável formação de vacúolos digestivos (Figura 2E). Além disso, a presença de inúmeros vacúolos secretores, de variados tamanhos, localizados na região apical celular pode ser observada (Figura 2F). As microvilosidades da porção apical apresentam-se pouco desenvolvidas, irregulares e praticamente destruídas.

Na região posterior (Figura 2G), a membrana citoplasmática basal mostrou grandes dobras (Figura 2H) e o citoplasma altamente vacuolizado. Também houve a formação de vesículas secretoras por todo o citoplasma, com aspecto de expelir para a luz intestinal. No interior dessas vesículas, ocorreu a formação de grandes e vários vacúolos digestivos (Figura 2I), com restos celulares observados no interior dos mesmos.

Larvas submetidas à fração contendo taninos catéquicos, cujo constituinte majoritário é uma proantocianidina na forma trimérica, apresentaram diversas alterações ultraestruturais, após $22 \mathrm{~h}$, evidenciando grande destruição celular. A região anterior apresentou-se com grande quantidade de vacúolos digestivos, núcleo com cromatina descondensada (Figura 3A). A célula em geral apresentou-se sem forma definida e com aparência de degeneração. $\mathrm{Na}$ região basal celular notou-se a presença de grande quantidade de mitocôndrias em diversas formas, eletrodensidade e tamanhos (Figura 3A), além de pregas na lâmina basal com espaços evidentes entre as dobras desta membrana (Figura 3B). A região apical celular apresentou maior concentração de vacúolos digestivos, de vários tamanhos e formas (Figura 3C). As microvilosidades desta região apresentaram-se menores e parcialmente destruídas (Figura 3C).

A região mediana diferiu-se do controle, pela destruição celular (Figura 3D), citoplasma com uma grande quantidade de vacúolos digestivos, de vários tamanhos e formas, núcleo com cromatina condensada e nucléolo evidente (Figura 3E). Foi possível observar a formação de vesículas secretoras na porção apical, onde o conteúdo citoplasmático se projeta para o meio externo (Figura 3F). As microvilosidades não apresentaram alterações evidentes.

$\mathrm{Na}$ região posterior, o epitélio apresentou-se estratificado, células com citoplasma heterogêneo, núcleos irregulares e com presença de vacúolos (Figura 3G). Na região basal, houve um deslocamento celular da lâmina basal, formando um isolamento entre a célula epitelial e o restante do conteúdo da larva. Notouse a lâmina basal celular destruída (Figura $3 \mathbf{H}$ ). A região apical apresentou-se com microvilosidades mais curtas e citoplasma altamente vacuolizado (Figura 3I). 

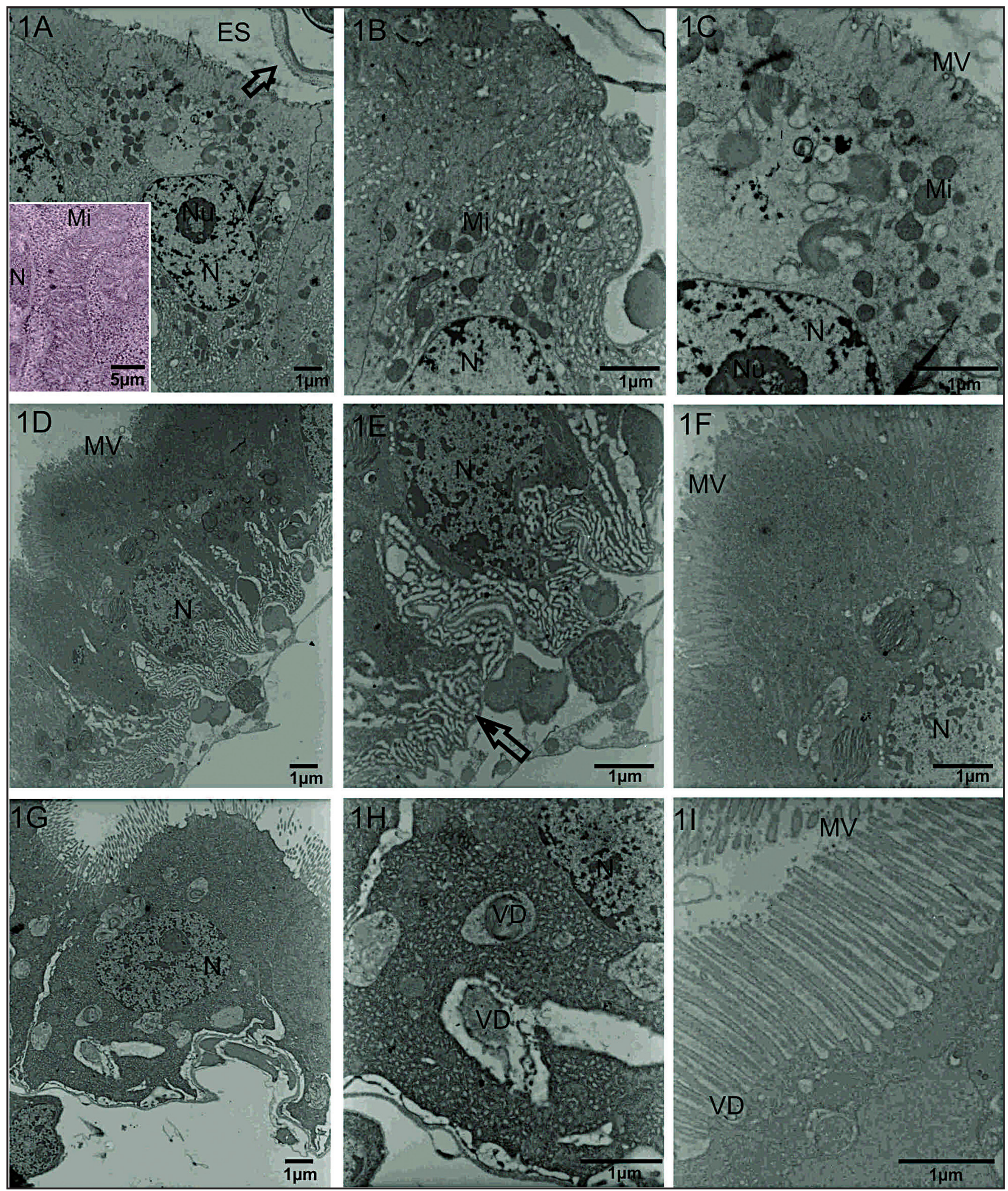

FIGURA 1 - Eletromicrografias das células epiteliais do mesêntero de larvas de $3^{\circ}$ estádio de Aedes aegypti do grupo controle. Figura 1A: Vista geral das células epiteliais da região anterior do mesêntero. Notar a presença de inúmeras mitocôndrias (detalhe) e da matriz peritrófica (seta). Figura 1B: Detalhe da região basal, evidenciando a presença de mitocôndrias e dobras da membrana plasmática. Figura 1C: Notar a presença de vacúolos e microvilosidades na região apical destas células. Figura 1D: Vista geral das células epiteliais da região mediana do mesêntero. Figura 1E: Aspecto da região basal, destacando as dobras da membrana plasmática basal, indicando trocas iônicas (seta). Figura 1F: Detalhe da região apical destas células evidenciando as microvilosidades e vacúolos digestivos de mitocôndria. Figura 1G: Vista geral das células epiteliais da região posterior do mesêntero. Figura 1H: Detalhe da região basal com vacúolos digestivos. Figura 1I: Detalhe da região apical destas células, evidenciando a presença de longas microvilosidades de vacúolos digestivos com presença de Figuras mielínicas.

Nu: nucléolo, N: núcleo, ES: espaço subperitrófico, Mi: mitocôndria, MV: microvilosidades, VD: vacúolo digestivo. 

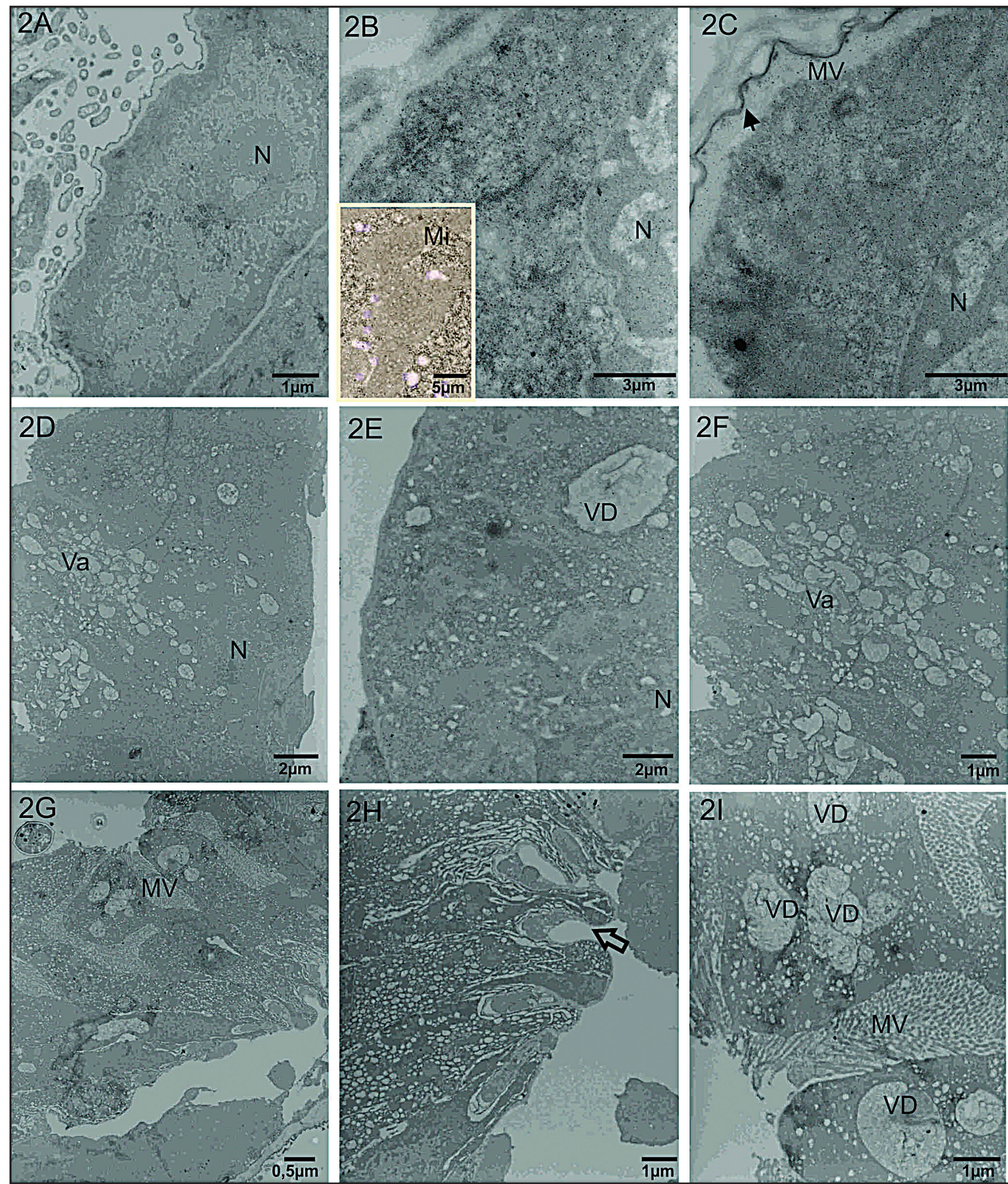

FIGURA 2 - Eletromicrografias das células epiteliais do mesêntero de larvas de $3^{\circ}$ estádio de Aedes aegypti submetidas por $22 \mathrm{~h}$ ao diterpeno da Copaifera reticulata. Figura 2A: Vista geral das células da região anterior do mesêntero. Figura 2B: Detalhe da região basal destacando presença de mitocôndrias (detalhe). Figura 2C: Detalhe da região apical, evidenciando a matriz peritrófica (cabeça de seta). Figura 2D: Vista geral das células da região mediana do mesêntero. Figura 2E: Região basal celular evidenciando a lâmina basal e vacúolo digestivo. Figura 2F: Região apical celular com intensa vacuolização. Figura 2G: Vista geral das células da região posterior do mesêntero. Figura 2H: Região basal celular com dobras da membrana plasmática basal (seta). Figura 2I: Detalhe da região apical celular evidenciando grande quantidade de microvilosidades e a formação de grandes vesículas secretoras.

Nu: nucléolo, N: núcleo, ES: espaço subperitrófico, Mi: mitocôndria, MV: microvilosidades, VD: vacúolo digestivo, Va: vacúolos. 

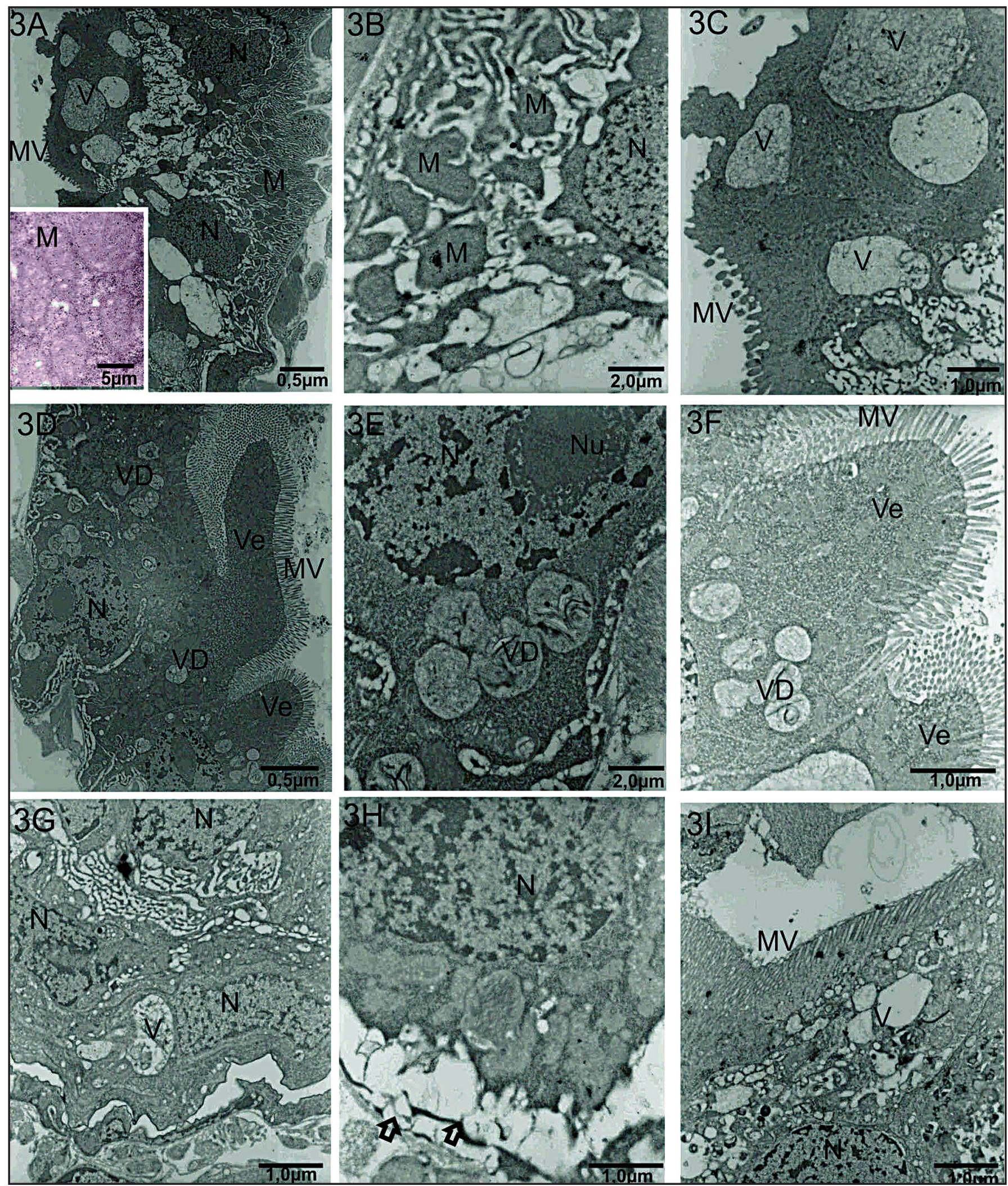

FIGURA 3 - Eletromicrografias das células epiteliais do mesêntero de larvas de $3^{\circ}$ estádio de Aedes aegypti submetidas por $22 \mathrm{~h}$ ao tanino catéquico de Magonia pubescens. Figura 3A: Vista geral das células da região anterior do mesêntero, evidenciando o alto grau de destruição celular. Notar no detalhe a presença de mitocôndrias. Figura 3B: Detalhe da região basal celular com grande quantidade de mitocôndrias e de dobras da membrana plasmática basal. 3C: Detalhe da região apical celular com a presença de grandes vacúolos. Figura 3D: Vista geral das células da região mediana do mesêntero. Figura 3E: Detalhe da região basal celular destacando a presença de vacúolos digestivos. Figura 3F: Detalhe da região apical celular evidenciando os vacúolos digestivos e a formação de projeções apicais secretoras. Figura 3G: Vista geral das células da região posterior do mesêntero com a presença de vacúolos digestivos e núcleos irregulares. Figura 3 H: Detalhe da região basal evidenciado o descolamento da célula da membrana basal (setas). Figura 3I: Detalhe da região apical celular evidenciando de vacúolos.

Nu: nucléolo, N: núcleo, ES: espaço subperitrófico, Mi: mitocôndria, MV: microvilosidades, VD: vacúolo digestivo, Ve: vesículas, V: vacúolos. 


\section{DISCUSSÃo}

Estudos ultraestruturais das células do mesêntero de insetos em estágios larvais são bastante escassos. As observações sobre a ultraestrutura normal das células do mesêntero das larvas de $3^{\circ}$ estádio de Aedes aegypti realizadas neste trabalho coincidiram com as observações descritas na literatura ${ }^{12}$, que também descrevem a presença de mitocôndrias grandes e irregulares e microvilosidades na porção apical nas células do mesêntero associadas à função de absorção. Neste trabalho, as microvilosidades foram observadas nas três regiões do mesêntero, sendo maiores e mais espessas na região posterior (Figuras 1C, 1F e 1I) destacando assim a maior capacidade absortiva das células.

Estudos descritivos sobre os tipos de células encontrados nos insetos relataram uma associação de grandes dobras da membrana plasmática basal com mitocôndrias, fato também observado neste trabalho que indica a realização de transporte de água e íons por esta membrana $^{24}$ (Figura 1E).

Os efeitos do diterpeno sobre as células do mesêntero das larvas de Aedes aegypti incluíram intensas modificações citoplasmáticas como vacuolização, presença de grandes vacúolos de variadas formas, desorganização celular, formação de vesículas de secreção e mudança estrutural das microvilosidades.

Os principais efeitos do diterpeno e da fração rica em taninos foram à degeneração celular, vacuolização citoplasmática, alteração das microvilosidades, núcleos irregulares e deslocamento das células da lâmina basal. Isto seria consequência da intoxicação celular causada tanto pelo diterpeno quanto pelos taninos, levando à formação de vesículas e à lise celular. Efeitos similares foram obtidos com as plantas Alnus glutinosa, Magonia pubescens, Populus nigra e Quercus robur ${ }^{11,25,26}$.

A formação de vesículas secretoras na porção apical das células analisadas indica que o conteúdo citoplasmático celular está sendo expelido para a luz intestinal como forma de defesa à ação do diterpeno e do tanino. A presença dessas vesículas, associada à intensa vacuolização citoplasmática, demonstra a aceleração do processo de lise celular provocado pelo efeito tóxico das substâncias analisadas. Estudos ultraestruturais sobre larvas de Aedes aegypti tratadas com Bacilllus thuringiensis relataram a presença dessas mesmas alterações além de deformidades no núcleo destas células com mudança na forma e formação de mais poros no envelope nuclear ${ }^{26}$. Nas larvas tratadas com taninos, as células apresentaram núcleos irregulares, sem o aumento no número de poros no envelope nuclear.

O mesêntero é o principal órgão responsável pela absorção de nutrientes pelos insetos em geral ${ }^{26}$. Vários trabalhos sobre o efeito larvicida de diversas substâncias, em Diptera, relatam que as principais alterações morfohistológicas ocorrem no mesêntero, desta forma, fica claro o importante papel desta porção do tubo digestório no processo de absorção ${ }^{1,11,12,25}$. As alterações provocadas por estas substâncias, independente se são de origem química ou biológica, são sempre semelhantes. Isto comprova que estas alterações são respostas das células diante da intoxicação sofrida.

\section{CONFLITO DE INTERESSE}

Os autores declaram não haver nenhum tipo de conflito de interesse no desenvolvimento do estudo.

\section{SUPORTE FINANCEIRO}

CNPq e FAPEG.

\section{REFERÊNCIAS}

1. Derouich M, Boutayeb A, Twizell EH. A model of dengue fever. Bio Med Eng Online 2003; 19:2-4

2. Ministério da Saúde. Guia de vigilância epidemiológica. Brasília: Fundação Nacional de Saúde; 2009.

3. World Health Organization. Dengue/dengue hemorrhagic fever prevention and control. New Delhi: Regional Office for South-East Asia; 2000

4. Donalísio MR, Glasser CM. Vigilância entomológica e controle de vetores do dengue. Rev Bras Epidemiol 2002; 5:259-272.

5. Ministério da Saúde. Secretaria de Vigilância em Saúde. Informe epidemiológico da dengue, 1 a 52 semanas de 2009. [Acesso 20 março 2010]. Disponível em http://portal.saude.gov.br/portal/arquivos/pdf/.

6. Serufo JC, Nobre V, Rayes A, Marcial TM, Lambertuccil JR. Dengue: uma nova abordagem. Rev Soc Bras Med Trop 2000; 33:465-476.

7. Braga IA, Lima JBP, Silva SS, Valle D. Aedes aegypti resistance to temephos during 2001 in several municipalities in the states of Rio de Janeiro, Sergipe, and Alagoas, Brazil. Mem Inst Oswaldo Cruz 2004; 99:199-203.

8. Carvalho MSL, Caldas ED, Degallier N, Vilarinhos PTR, Souza LCKR, Yoshizawa MAC, et al. Suscetibilidade de larvas de Aedes aegypti ao inseticida temephos no Distrito Federal. Rev Saude Publica 2004; 38:623-629.

9. Cunha MP, Lima JBP, Brogdon WG, Moya GE, Valle D. Monitoring of resistance to the pyrethroid cypermethrin in Brazilian Aedes aegypti (Diptera: Culicidae) populations collected between 2001 and 2003. Mem Inst Oswaldo Cruz 2005 ; 100:441-444.

10. Luna JED, Martins MF, Anjos AF, Kuwabara EF, Navarro-Silva MA Susceptibilidade de Aedes aegypti aos inseticidas temephos e cipermetrina, Brasil. Rev Saude Publica 2004; 38:842-843.

11. Arruda W, Oliveira GMC, Silva IG. Toxicidade do extrato etanólico de Magonia pubescens sobre larvas de Aedes aegypti. Rev Soc Bras Med Trop 2003; $36: 17-25$.

12. Arruda W, Oliveira GMC, Silva IG. Estudo ultra-estrutural do efeito da toxicidade do extrato da Magonia pubescens (St. Hil.) no mesêntero de larvas de Aedes aegypti (L.) (Diptera, Culicidae). Rev Patol Trop 2008; 37:255-267.

13. Cavalcanti ESB, Morais SM, Lima MAA, Santana EWP. Larvicidal Activity of Essential Oils from Brazilian Plants against Aedes aegypti L. Mem Inst Oswaldo Cruz 2004; 99:541-544.

14. Lima MGA, Maia ICC, Sousa BD, Morais SM, Freitas SM. Effect of stalk and leaf extracts from Euphorbiaceae species on Aedes aegypti (Diptera, Culicidae) larvae. Rev Inst Med Trop S Paulo 2006; 48:211-214.

15. Pohlit AM, Quignard ELJ, Nunomura SM, Tadei WP, Hidalgo AF, Pinto ACS, et al. Screening of plants found in the State of Amazonas, Brazil for larvicidal activity against Aedes aegypti larvae. Acta Amaz 2004; 34: 97-105.

16. Silva HHG, Silva IG, Santos RMG, Rodrigues Filho E, Elias CN. Atividade larvicida de taninos isolados de Magonia pubescens St. Hil. (Sapindaceae) sobre Aedes aegypti (Diptera, Culicidae). Rev Soc Bras Med Trop 2004; 37:396-399.

17. Silva IG, Zanon VOM, Silva HHG. Larvicidal Activity of Copaifera reticulata Ducke Oil-Resin against Culex quinquefasciatus Say (Diptera: Culicidae). Neotrop Entomol 2003; 32:729-732.

18. Silva HHG, Geris R, Rodrigues Filho E, Rocha C, Silva IG. Larvicidal activity of oil-resin fractions from the Brazilian medicinal plant Copaifera reticulata Ducke (Leguminosae-Caesalpinoideae) against Aedes aegypti (Diptera, Culicidae). Rev Soc Bras Med Trop 2007; 40:264-267.

19. Geris R, Rodrigues Filho E, Silva HHG, Silva IG. Larvicidal effects of fungal meroterpenoids in the control of Aedes aegypti L., the main vector dengue and yellow fever. Chem Biodivers 2008; 5: 341-345

20. Silva HHG, Silva IG, Lira KS. Metodologia de criação, manutenção de adultos e estocagem de ovos de Aedes aegypti (Linnaeus, 1762) em laboratório. Rev Patol Trop 1998; 27:53-63. 
21. Benchimol M, Attias M, Silva NLC, Carvalho TMU.Métodos de estudo da célula. Rio de Janeiro: Fundação Estadual Norte Fluminense. Universidade Estadual do Norte Fluminense; 1996.

22. Bozzola JJ, Russel LD. Electron Microscopy: principles and techiniques for biologist. Boston: Jones and Bartlett Publishers; 1992.

23. Souza W. Manual sobre técnicas básicas em microscopia eletrônica. Rio de Janeiro: Sociedade Brasileira de Microscopia Eletrônica; 1989.

24. Cavalcante VM, Cruz-Landim C. Types of cells present in the midgut of the insects: a review. Naturalia 1999; 24:19-40.

25. David JP, Delphine R, Pautou MP, Meyran JC. Differential toxicity of leaf litter to dipteran larvae of mosquito developmental sites. J Invertebr Pathol 2000; 75: 9-18.

26. Delphine R, Pautou MP, Meyran JP. Histopathological effects of tannic acid on the midgut epithelium of some aquatic Diptera larvae. J Invertebr Pathol 1999; 73:173-181. 